\title{
CONTROLE DA FERRUGEM DA FOLHA DE PESSEGUEIRO MEDIANTE PULVERIZAÇÕES COM DIFERENTES FUNGICIDAS ${ }^{1}$
}

\author{
IDEMIR CITADIN ${ }^{2}$, ORNELLA BERTUOL ${ }^{3}$, MARCELO HENRIQUE BASSANI ${ }^{4}$, RODRIGO NUNES DE SOUSA ${ }^{3}$, \\ LÍGIA CAROLINA ALCÂNTARA PINOTTI ${ }^{3}$, TÁSSIA SOLETTI ${ }^{3}$
}

\begin{abstract}
RESUMO - O objetivo deste experimento foi avaliar a combinação de diferentes fungicidas no controle da ferrugem da folha em pomares de pessegueiros e sua viabilidade econômica. As plantas que receberam os tratamentos Amistar + Folicur (T1) e Amistar + Manzate (T2) apresentaram maior retenção foliar e menor severidade de ferrugem nas folhas remanescentes. A cultivar Ouro mostrou-se mais suscetível à doença que as cultivares Chimarrita e Premier. Houve aumento na produtividade e na renda bruta do produtor, justificando a adoção da prática testada.
\end{abstract}

Termos para Indexação: prunoideas, Prunus persica, frutas de caroço, doenças, floração, Transzchelia discolor, Azoxystrobin, Mancozeb, Tebuconazole.

\section{PECH LEAF RUST CONTROL WITH DIFERENTS FUNGICIDES SPRAYS}

ABSTRACT - The aim of the present study was to test different fungicides in peach leaf rust control and their economic use in peach orchard. The treatments T1 (Amistar and Folicur) and T2 (Amistar and Manzate) had a better leaf retention and less severity of leaf rust in reminiscent leaf. 'Ouro' cultivar was more susceptible than the others cultivars ('Chimarrita' and 'Premier'). There was an improving in productivity and gross income, justifying the fungicides use in commercial orchards to control peach leaf rust.

Index Terms: prunoideas, Prunus persica, stone fruits, disease, blooming, Transzchelia discolor. Azoxystrobin, Mancozeb, Tebuconazole.

A fruticultura é uma atividade que vem se expandindo no sudoeste do Paraná. Atualmente, os 42 municípios componentes da região mantêm programas desta natureza, proporcionando aos agricultores familiares diversificarem as propriedades, agregando maior renda às suas atividades. As frutas de caroço, notadamente o pêssego (Prunus persica vulgaris L.), a nectarina (Prunus persica nucipersica L.) e a ameixa (Prunus salicina L.), ocupam atualmente cerca de 496 ha, com uma produção média de 3.500 toneladas/ha (DERAL, 2003).

O Programa Redes de Referência para a Agricultura Familiar, através de professores e alunos do Curso de Agronomia do Centro Federal de Educação Tecnológica do Paraná (CEFET-PR), acompanha algumas Unidades de Exploração Agrícola (UEA's) que se dedicam à fruticultura de caroço, na região. Nelas, os pomares já se encontram em plena produção, alcançando níveis de produtividade abaixo do esperado. Um dos problemas que mais vem preocupando os fruticultores, é a ocorrência da desfolha do pessegueiro na pós-colheita, seguida da brotação precoce e irregular da planta, ocasionando frutificações igualmente irregulares e prejuízos econômicos. Uma das principais causas destes sintomas é a ferrugem das folhas (Transzchelia discolor F.), sendo que, pelos prejuízos que vem causando aos pomares, merece atenção e precauções devidas.

A ferrugem do pessegueiro é uma doença de importância econômica em várias regiões produtoras do mundo (Bolkan et al., 1985; Kable et al., 1986; Bertrand, 1995). Este fungo infecta principalmente as folhas da planta, no período pós-colheita, produzindo manchas amareloferruginosas na face inferior (abaxial) e amarelo-pálidas na face superior (adaxial). A germinação dos uredósporos ocorre, preferencialmente, com temperaturas variando de 13 a $26^{\circ} \mathrm{C}$ e um período de molhamento em torno de $18 \mathrm{~h}$. O período de incubação do patógeno na folha dura em torno de 7 a 10 dias. Os uredósporos são liberados em condições de baixa umidade relativa do ar e transportados pelo vento seco. A disseminação é também favorecida pela água da chuva (Bertrand, 1995). $\mathrm{O}$ agente causal pode sobreviver durante o inverno em outros hospedeiros, condições que não são essenciais para o seu ciclo em climas quentes (Anderson, 1956), ou em lesões nos ramos (Ogawa \& English, 1991). Em casos de alta severidade, no final da safra, a ferrugem provoca abscisão foliar, resultando na desfolha parcial ou quase completa da planta (Martins \& Amorim, 1996). A queda precoce das folhas resulta em uma primeira floração de outono não-aproveitada, mas que extrai nutrientes e enfraquece a formação dos ramos produtores da próxima safra (Bleicher \& Tanaka, 1982; Feliciano \& Araujo, 1979). Então, a floração principal acontece de forma irregular, diminuindo a produção do pomar. O controle desta doença pode-se dar através do uso de cultivares resistentes e também através da utilização de fungicidas.

Com relação ao controle através do uso de fungicidas, é recomendada a pulverização alternada com fungicidas de diferentes modos de ação, visando a evitar o surgimento de biótipos resistentes. Existem três tipos de fatores envolvidos na resistência de fungos a fungicidas, sendo definidos como relativos ao fungo, relativos ao fungicida e relativos ao uso do fungicida. O risco do surgimento de resistência relativa ao fungicida é proporcional à especificidade do modo de ação do fungicida. Por essa razão, os fungicidas sistêmicos, mais específicos e seletivos, são mais predispostos à resistência. Entretanto, a resistência pode, também, ser desenvolvida para fungicidas protetores, desde que possuam grande especificidade na ação sobre o patógeno (Reis \& Forcelini, 1993).

A ocorrência dos danos por ferrugem vem sendo registrada em vários pomares de pessegueiros da região, e o seu controle não é de perfeito domínio de alguns fruticultores, demandando, por isso, a instalação de Unidades de Teste e Validação (UTVs), para a determinação do melhor controle para a doença e sua difusão.

Com a implantação desta UTV, pretendeu-se retomar a viabilidade da produção comercial de pêssego no sudoeste do Paraná e, mais especificamente, no município de Chopinzinho-PR. A verificação dos níveis de incidência concreta da ferrugem em pomares de pessegueiros em uma UEA do sistema de produção típico PSM2 - Grãos/ Leite/Frutas de Caroço (Perin et al., 2001), bem como a determinação e difusão dos métodos de controle contribuíram para alcançar este objetivo.

O objetivo deste experimento foi avaliar a combinação de diferentes fungicidas no controle da ferrugem da folha em pomares de pessegueiros e avaliar a viabilidade econômica desta prática.

A UTV foi implantada em uma UEA no município de Chopinzinho, sudoeste do Paraná. A UEA possui área de um hectare de frutas de caroço, como as cultivares Ouro, Chimarrita e Premier. Foram utilizadas 60 plantas por tratamento para cada cultivar. O delineamento experimental foi o inteiramente casualizado, em esquema fatorial $3 \times 3$,

\footnotetext{
${ }^{1}$ (Trabalho 147/2004). Recebido: 28/10/2004. Aceito para publicação: 09/06/05.

${ }^{2}$ Eng $^{\mathbf{0}}$ Agrônomo, Dr. em Fruticultura de Clima Temperado, Prof. CEFET-PR, Unidade Sudoeste. idemir@pb.cefetpr.br.

${ }^{3}$ Eng ${ }^{a}$ Agrônoma, Msc. Agroecossistemas, Projeto Redes de Referência, IAPAR/EMATER.

${ }^{4}$ Acadêmicos do curso de Agronomia do CEFET-PR, Unidade Sudoeste, Campus Pato Branco.
} 
sendo os fatores cultivar (Ouro, Chimarita e Premier) e fungicidas [T0 testemunha (sem fungicidas na pós-colheita): T1 - Amistar $(25 \mathrm{~g} / 100 \mathrm{~L}$ de água) e Folicur (100 mL/100L de água); T2 - Amistar $(25 \mathrm{~g} / 100 \mathrm{~L} \mathrm{de}$ água) e Manzate (200 g/100L de água)]. O Amistar (Azoxystrobin a 50\% $\mathrm{m} / \mathrm{m}$ ) é um fungicida sistêmico do grupo das estrobilurinas, com atividade preventiva, curativa e antiesporulante. O Folicur CE (Tebuconazole a $20 \% \mathrm{~m} / \mathrm{V}$ ) é um fungicida sistêmico do grupo dos triazóis, com ação preventiva, curativa e erradicativa, e o Manzate 800 (Mancozeb a $80 \% \mathrm{~m} / \mathrm{m}$ ) é um fungicida do grupo dos ditiocarbamatos, com ação de contato (Andrei, 1993). Em todos os tratamentos, as aplicações foram ministradas a cada 20 dias, sendo os fungicidas aplicados de forma alternada, sem mistura.

Para cada tratamento, foram sorteadas cinco plantas. Destas, foram coletados cinco ramos, nos quais se procedeu a avaliação visual do percentual de desfolha e severidade do ataque de ferrugem nas folhas remanescentes. A severidade média foi calculada a partir da análise do percentual de área foliar atacada pela doença nas folhas remanescentes de cada ramo. A avaliação foi feita no dia 18-02-2003, após duas aplicações de fungicidas. Após esta data, procedeu-se a mais duas aplicações de fungicidas, totalizando 4 aplicações. Os dados expressos em percentagem foram transformados através do arco-seno da raiz de x/100 e submetidos à análise de variância e teste de comparação de média (Duncan Pd" 0,05).

Verificou-se que, para a cultivar Chimarrita, o tratamento 1 proporcionou menor porcentagem de desfolha $(13,4 \%)$, não se diferenciando significativamente do tratamento $2(19,9 \%)$, porém diferindo significativamente da testemunha $(49,6 \%)$, sem aplicação de fungicida. Para a cultivar Premier, não foi observada diferença significativa entre os tratamentos com fungicidas (T1: 18,3\% e T2: $17,0 \%$ ), porém, diferindo significativamente da testemunha, onde o nível de desfolha foi de $34,7 \%$. No caso da cultivar Ouro, o tratamento que mais se destacou foi o tratamento $1(14,0 \%)$, não diferindo do tratamento $2(29,6 \%)$. A desfolha na testemunha foi de $83,6 \%$ e diferiu significativamente dos tratamentos T1 e T2 (Figura 1).

Importante ressaltar que não foram observadas diferenças significativas entre os tratamentos $\mathrm{T} 1 \mathrm{e} \mathrm{T} 2$, entre as cultivares estudadas. A cultivar Ouro foi a que apresentou o maior percentual de desfolha, no tratamento sem fungicida (T0), diferindo significativamente das demais,

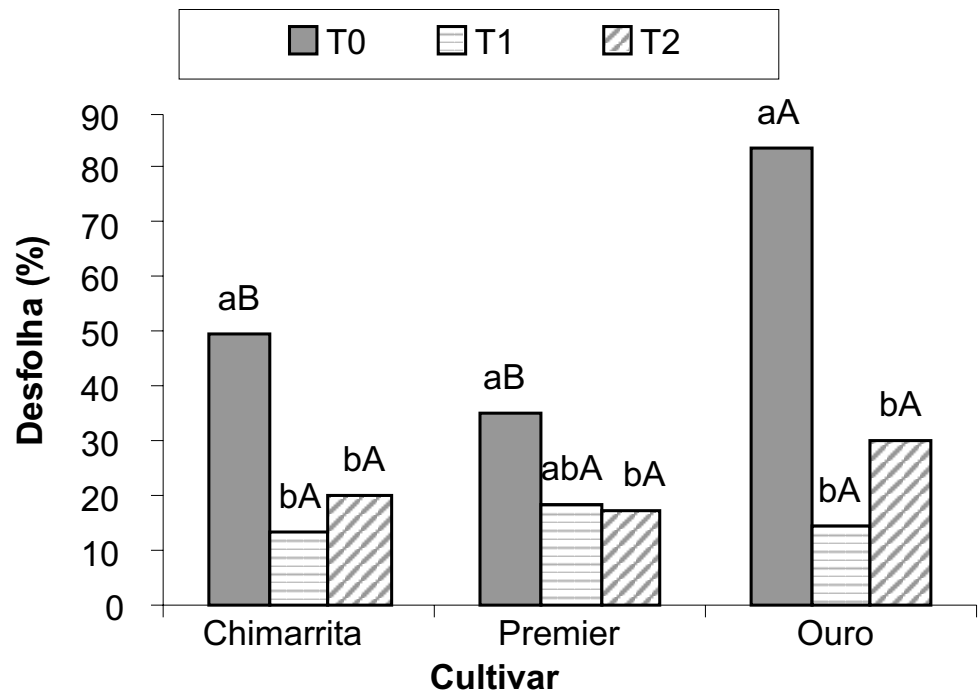

FIGURA 1 - Percentual de desfolha em pessegueiro (Prunus persica vulgaris L.) causada pela ferrugem da folha (Transzchelia discolor Fuckel). Médias seguidas da mesma letra minúscula, entre tratamentos dentro de cada cultivar, e maiúscula, entre cultivares dentro de cada tratamento, não diferem entre si, pelo teste de Duncan $\leqslant 0,05$. T0 Testemunha (sem adição de fungicidas pós-colheita); T1 - Amistar (25g/100L de água) e Folicur (100mL/100L de água); T2 - Amistar (25g/100L de água) e Manzate (200g/ $100 \mathrm{~L}$ de água). C.V. $=26 \%$. e foi a que melhor respondeu à aplicação de fungicidas, reduzindo o percentual de desfolha ao mesmo nível que as demais cultivares, para os tratamentos T1 e T2 (Figura 1).

Quanto à severidade de ferrugem da folha, observou-se que, na cultivar Chimarrita, foi de 4,4\% na testemunha (T0), enquanto nos tratamentos T1 e T2, esta sofreu redução significativa para $1,26 \%$ e $0,97 \%$, respectivamente (Figura 2 ).

Considerando a cultivar Premier, a severidade de ferrugem foi de 3\% na testemunha (T0), não havendo diferença significativa em relação ao tratamento 2 , no qual ela foi de $1,8 \%$. Já o tratamento 1 apresentou redução significativa em relação à testemunha $(0,8 \%)$, mas não diferindo estatisticamente do tratamento 2 (Figura 2).

Para a cultivar Ouro, a severidade de ferrugem na folha de pessegueiro foi de $11,2 \%$, na testemunha (T0), enquanto no tratamento 2 , foi de $5,7 \%$, diferindo significativamente da testemunha. A menor severidade de ferrugem da folha, porém, foi observada no tratamento 1 , cujo percentual foi de $2,3 \%$, diferindo significativamente dos demais tratamentos (Figura 2).

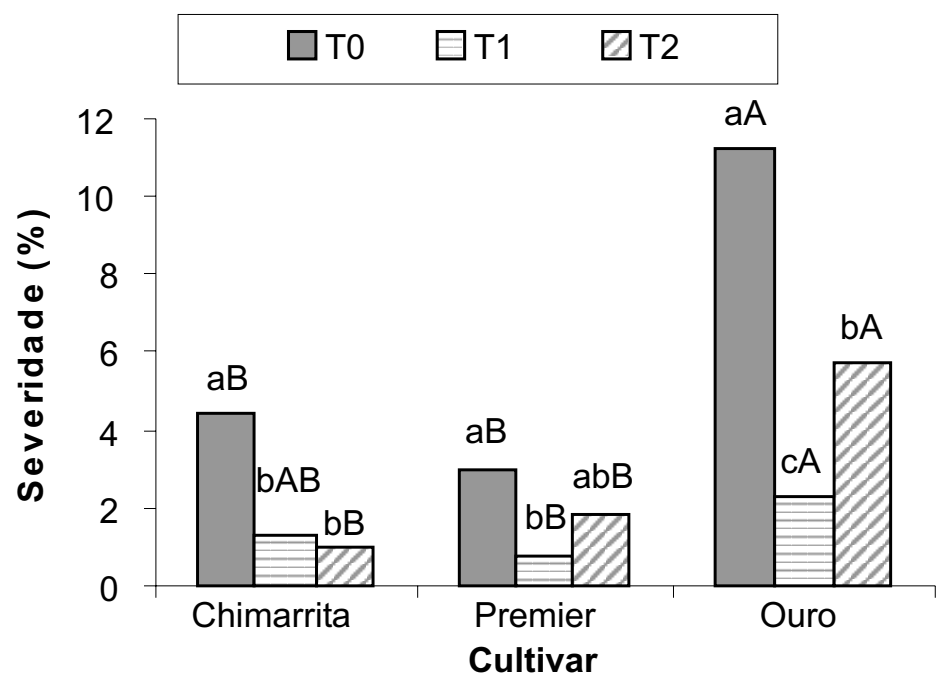

FIGURA 2 - Severidade da ferrugem da folha do pessegueiro causada por Transzchelia discolor Fuckel em diferentes cultivares de pessegueiro (Prunus persica BL.). Médias seguidas da mesma letra minúscula, entre tratamentos dentro de cada cultivar, e maiúscula, entre cultivares dentro de cada tratamento, não diferem entre si, pelo teste de Duncan $P \leqslant$ 0,05 . T0 - Testemunha (sem aplicação de fungicidas após a colheita); T1 - pulverização com Amistar $(25 \mathrm{~g} / 100 \mathrm{~L}$ de água) e Folicur (100mL/100L de água); T2 - pulverização com Amistar $(25 \mathrm{~g} / 100 \mathrm{~L}$ de água) e Manzate $(200 \mathrm{~g} / 100 \mathrm{~L}$ de água). C.V $=24 \%$.

Na testemunha (T0), observou-se maior severidade de ferrugem da folha na cultivar Ouro $(11,2 \%)$, diferindo significativamente das demais cultivares $($ Chimarrita $=4,4 \%$; Premier $=3,0 \%)$ e repetindo o observado quanto ao percentual de desfolha. Isso demonstra a maior suscetibilidade desta cultivar à doença considerada. Diferentes graus de resistência à ferrugem da folha foram observados por CentellasQuezada (2000), entre os genótipos estudados, justificando trabalhos de melhoramento, visando ao lançamento de cultivares resistentes a esta doença.

Mesmo no tratamento com fungicidas (T1 e T2), a cultivar Ouro apresentou maior severidade da doença que as cultivares Chimarrita e Premier, exceto para o tratamento 1, com a Chimarrita. As cultivares Chimarrita e Premier não diferiram significativamente entre si quanto à severidade da ferrugem em todos os tratamentos (Figura 2)

$\mathrm{Na}$ avaliação visual feita em 17 de abril de 2003, após 4 pulverizações, conforme os tratamentos, observou-se que as plantas que receberam os tratamentos com fungicida apresentavam retenção foliar e não haviam induzido o florescimento, enquanto as plantas do 
tratamento sem fungicida (T0) haviam induzido a floração e um segundo surto de brotação. A floração e a brotação antecipadas são indesejáveis, pois são destruídas pelas geadas, além de consumir as reservas de carboidratos (amido) dos ramos produtivos, importantes para a retomada do crescimento ativo após a saída do dormência.

Conforme observado por Bertrand (1995), a ferrugem pode ser controlada através da pulverização com fungicidas. O mesmo autor relata que, em locais de ocorrência precoce desta doença, fazem-se necessárias até três pulverizações antes mesmo da colheita. Esta situação não foi observada no pomar onde foi conduzido o experimento, portanto as pulverizações que caracterizaram os tratamentos, foram feitas somente após a colheita, o que resulta em economia e menor risco ambiental e humano. Como resultado, observou-se incremento de produtividade de $5.940 \mathrm{~kg} / \mathrm{ha}$, conferindo um incremento na receita bruta de 3.393,00 reais/ha (resultados não mostrados). O resultado econômico obtido justifica a prática de controle da ferrugem do pessegueiro na pós-colheita. Porém, há a necessidade de se estabelecer programa de monitoramento que correlacione temperatura e molhamento foliar com a incidência e a severidade da ferrugem da folha, visando a alertar os produtores para efetuar o controle preventivo desta doença, em áreas endêmicas, aumentando ainda mais a economia desta prática.

As plantas que receberam os tratamentos Amistar + Folicur (T1) e Amistar + Manzate (T2) apresentaram maior retenção foliar e menor severidade de ferrugem nas folhas remanescentes. A cultivar Ouro mostrou-se mais suscetível à doença que as cultivares Chimarrita e Premier, nas condições de campo onde foi desenvolvido o experimento. Houve aumento na produtividade e na renda bruta do produtor, justificando a adoção da prática testada.

\section{REFERÊNCIAS}

ANDERSON, H.W. Diseases of fruit crops. New York: McGraw Hill, 1956. 501p.

ANDREI, E. Compêndio de defensivos agrícolas: guia prático de produtos fitossanitários para uso agrícola. 4. ed. São Paulo: Organização Andrei Editora, 1993. 448p.

BERTRAND, P.F. Rust. In: OGAWA, J.M.; ZEHR, E.I.; BIRD, G.W.; RITCHIE, D.F.; URIU, K.; UYEMOTO, J.K; (Ed.). Compendium of stone fruit diseases. St. Paul: The American Phytopathological Society, 1995. P.23-24.
BLEICHER, J.; TANAKA, H. Doenças do pessegueiro no Estado de Santa Catarina. 2. ed. Florianópolis: EMPASC, 1982. 53p.

BOLKAN, H.A.; OGAWA, J.M.; MICHAILIDES, T.J.; KABLE, P.F. Physiological especialization in Transchelia discolor. Plant Disease, St Paul, v.69, n.6, p. 485-486, 1985

CENTELLAS-QUEZADA, A. Herança da época de floração e da resistência à ferrugem da folha em pessegueiro. 2000. 59f. Tese (Doutorado em Fruticultura de Clima Temperado)- Faculdade de Agronomia Eliseu Maciel, Universidade Federal de Pelotas, Pelotas, 2000.

DERAL - Departamento de Economia Rural. Secretaria de Estado da Agricultura e do Abastecimento (SEAB) - Regional Pato Branco, 2003.

FELICIANO, A.; ARAUJO, P.F. Ferrugem das fruteiras de caroço I. Eficiência de diferentes fungicidas no controle da ferrugem do pessegueiro causado por Transzchelia spp. In: CONGRESSO BRASILEIRO DE FRUTICULTURA, 5., 1979, Pelotas. Anais... Pelotas: Sociedade Brasileira de Fruticultura, 1979. p. 724-727.

KABLE, P.F.; ELLISON, P.J.; BAMBACH, R.W. Physiological especialization in Transchelia discolor in Australia. Plant Disease, St Paul, v.70, n.3, p. 202-204. 1986.

MARTINS, M.C.; AMORIM, L. A ferrugem do pessegueiro. Summa Phytopathologica, Botucatu, v.22, n.3/4, p.193-199, 1996.

OGAWA, J.M.; ENGLISH, H. Diseases of temperate zone: tree fruits and nut crops. California: University of California, Division of Agriculture and Natural Resources, 1991.46p.

PERIN, E.; VIEIRA, J.A.N.; LOVATO, L.F.; MACHADO, M.L.S.; ANDRADE, M.A.A.; RADOMSKI, M.I.; PARIZOTTO, M.L.V. Agricultura familiar na região sudoeste do Paraná. Londrina: IAPAR/EMATER, 2001. 42p.

REIS, E.M.; FORCELINI, C.A. Fungicidas: seu emprego no controle de doenças de plantas. 2. ed. Passo Fundo: Gráfica e Editora UPF, 1993.p.70-71. 